\title{
Numerical Analysis of Static Tensile Test of the Sample Made of Polyethylene Reinforced by Halloysite Nanoparticles
}

\author{
A. Śliwa ${ }^{a}$, W. KWAŚNY ${ }^{a}$, M. NABIAŁEK ${ }^{b}$ AND R. DzIWIS ${ }^{a}$ \\ ${ }^{a}$ Institute of Engineering Materials and Biomaterials, Faculty of Mechanical Engineering, \\ Silesian University of Technology, 18A Konarskiego Str., PL-44100 Gliwice, Poland \\ ${ }^{b}$ Institute of Physics, Faculty of Production Engineering and Materials Technology, \\ Czestochowa University of Technology, 19 Armii Krajowej Str., PL-42200 Częstochowa, Poland \\ (Received August 26, 2019; revised version September 19, 2019; in final form September 19, 2019) \\ This work presents the results of computer simulation of one of the most common strength tests, which \\ is a static tensile test. The sections used in a numerical analysis are so-called "dumbbells", typical for plastic \\ samples. The results of the analysis were referenced to the actual tensile test of the samples made of polyethy- \\ lene reinforced by halloysite nanoparticles. The material was produced with the high-pressure injection method. \\ The computer simulation results were referenced to literature properties of the industrially used polyethylene to \\ compare the results obtained with those commonly considered typical for the above-mentioned material. It was \\ found that stress values and deformation values obtained by means of computer simulation are similar to real \\ results. A measurement error for such values was approximately $7 \%$. Computer simulation and modeling is an in- \\ terdisciplinary field necessary for the development of science and technology, playing an important role in material \\ engineering, which aims to improve the ability to predict results and optimize solutions.
}

DOI: 10.12693/APhysPolA.136.996

PACS/topics: computational materials scienc, finite element method, static tensile test, Polietylen halloysite nanoparticle, nanocomposites

\section{Introduction}

At present, composite materials represent a group of materials subject to constant improvement and continued research, mainly due to unlimited possibilities of combining the particular components used for their fabrication and due to outstanding properties of the input material after modifying the percentage content of its particular constituent materials [1-8].

Scientists from across the world are interested in nanocomposites fabricated from a combination of organic polymer materials and a reinforcement in the form of clay minerals, because such products can be applied, in particular, in the automotive industry, due to their optimum mechanical properties and due to the ease of manufacturing such type of hybrid materials [9-16].

The finite element method (FEM) is a tool used in engineering and scientific computations, allowing to perform computer simulations identifying the effect of various phenomena and processes on the elements made from specific materials subject to the research [17-23]. The tool abandons analytical solutions to the problem for the sake of division into finite elements (sections for one-dimensional space) and into distinctive nodes of this division [24-29]. Various procedures are employed to

corresponding author; e-mail: agata.sliwa@polsl.pl solve a given issue, specifically, a mesh is applied, and boundary conditions are introduced as a result of which a solution is reached which is approximate to the actual solution [30-36].

\section{Investigation methodology - computer simulation}

Samples for a static tensile test were made of a composite material such as polyethylene reinforced by nanometric halloysite particles, constituting $10 \%$ of the total volume of the input material, produced in the highpressure injection process in semi-automatic mode, with the material parameters $(E=600-1400 \mathrm{MPa}$, Poisson's ratio of $0.40-0.45)$. A static tensile test was conducted with a Zwick/Roell Z020 tensile machine in accordance with DIN EN ISO 6892-1.

Five dumbbell-shaped samples with the test length of $80 \mathrm{~mm}$, the average thickness of the holding part of $9.86 \mathrm{~mm}$, and thickness of approximately $3.99 \mathrm{~mm}$, were stretched successively while maintaining the initially set parameters of the tensile machine work according to DIN EN ISO 6892-1 test standard (tensile force of approximately $100 \mathrm{kN}$ ). A sample stress-elongation ratio was obtained for each of the samples as a result of the experiment, as shown in Fig. 1. The results obtained in the test are presented in Table I, and Figures 2 and 3 show samples before rupture and after the stretching process. 


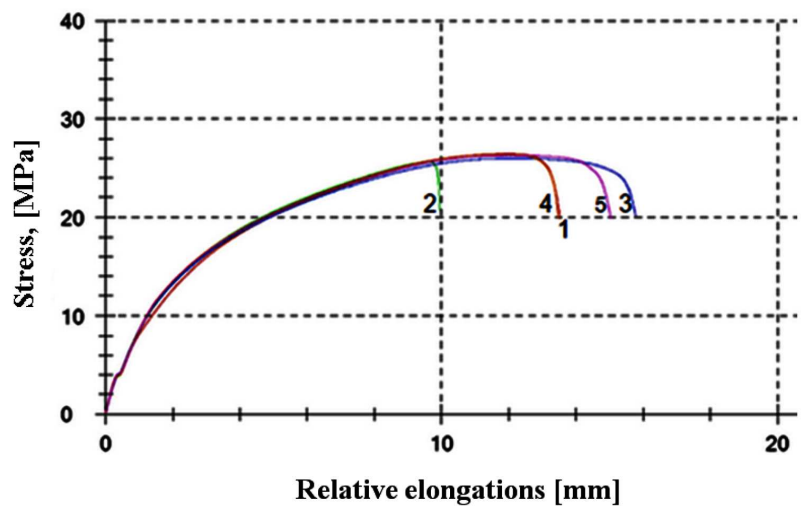

Fig. 1. The graph of the static tensile test results for samples of the nanocomposite made of the polyethylene strengthened by the nanoparticle halloysite filler.

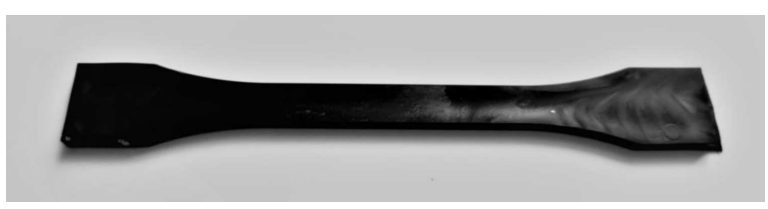

Fig. 2. The sample before the static tensile test.

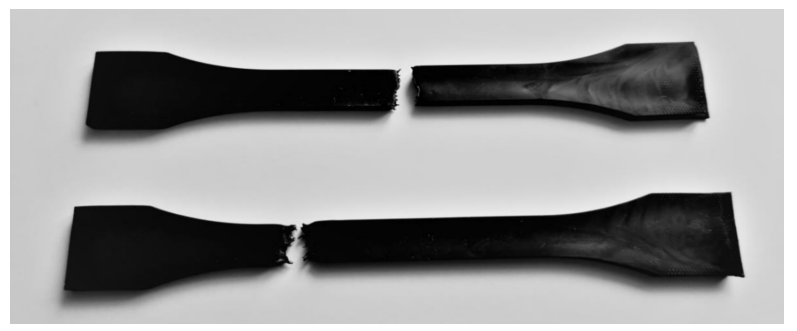

Fig. 3. Samples after the fracturing in the static tensile test.

TABLE I

Results of the static tensile test results for samples of the nanocomposite made of the polyethylene strengthened by the nanoparticle halloysite filler.

\begin{tabular}{c|c|c|c|c|c}
\hline \hline No. & $\begin{array}{c}m_{E} \\
{[\mathrm{GPa}]}\end{array}$ & $\begin{array}{c}R_{p 0.2} \\
{[\mathrm{MPa}]}\end{array}$ & $\begin{array}{c}R_{m} \\
{[\mathrm{MPa}]}\end{array}$ & $\begin{array}{c}F_{m} \\
{[\mathrm{kN}]}\end{array}$ & $\begin{array}{c}A_{80} \\
{[\%]}\end{array}$ \\
\hline 1 & 1 & 4 & 26 & 1.04 & 15.1 \\
2 & 1 & 4 & 26 & 1.01 & 10.6 \\
3 & 1 & 4 & 26 & 1.03 & 17.9 \\
4 & 1 & 4 & 26 & 1.04 & 15.1 \\
5 & 1 & 4 & 26 & 1.04 & 17.0
\end{tabular}

\section{Computer simulation}

A dumbbell-shaped section, corresponding to the actual sample dimensions, was subjected to a computer simulation of a static tensile test undertaken with
SolidWorks software, from which the prepared graphics was then imported to ANSYS software. Figure 4 shows a sample model with dimensions applied according to DIN EN ISO 6892-1; material data is also defined as the Young modulus of $600 \mathrm{MPa}$ and the Poisson's ratio of 0.42. A mesh of finite elements was applied onto a geometrical model of the Dominant/All type with the density of $1 \mathrm{~mm} /$ Hex, as shown below (Fig. 5).

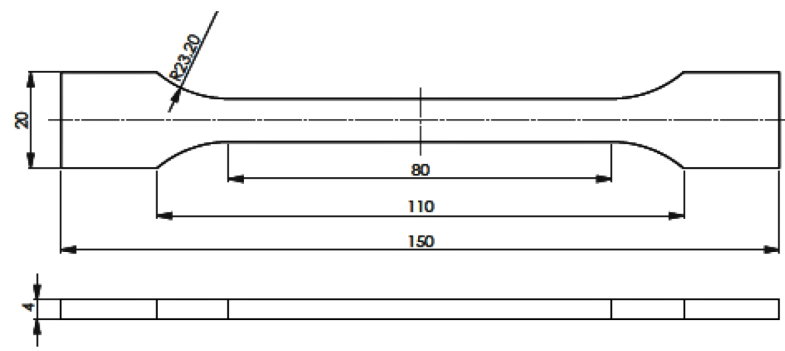

Fig. 4. Geometrical model of analyzed sample.

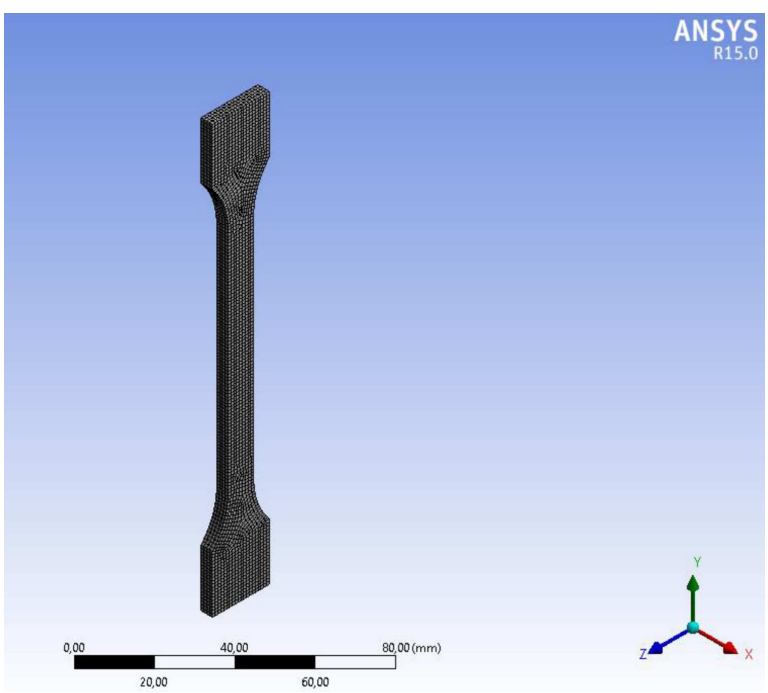

Fig. 5. The analyzed sample with generated mesh.

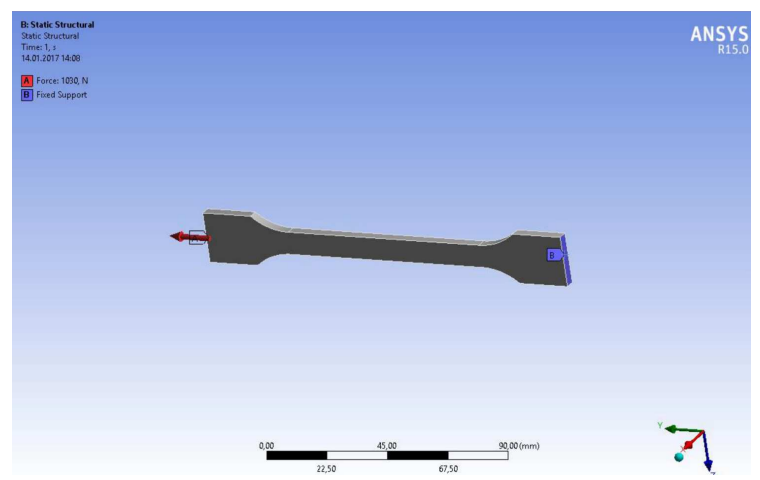

Fig. 6. The boundary conditions for analyzed sample: $\mathrm{A}$ - the tensile force, $\mathrm{B}$ - immobilisation of the sample. 
In the next step, boundary conditions were applied to the geometrical model, by immobilising one end of the sample, which is reflected in a static tensile test by a holding part fitted to the fixed tensile machine jaws; the force was also applied acting on the sample in the $Y$ axis, corresponding to the average force acting on the examined samples during the static tensile test described earlier with the value of $1.3 \mathrm{kN}$, so that the simulation reflects, as far as possible, the conditions of the test performed with the testing machine (Fig. 6).

\section{Results}

The results presented in the figures below were obtained with computer simulation in ANSYS software. Figures 7 and 8 show the distribution of normal stresses occurring in the sample in the direction of the $X$ and $Z$ axes; no considerable forces were noticed for the force applied on the sample, which would lead to sample deformation. A completely different situation was noticed for normal stresses existing in the sample in the $Y$ axis. The cumulation of normal stresses is visible, featuring the value of approximately $28 \mathrm{MPa}$,

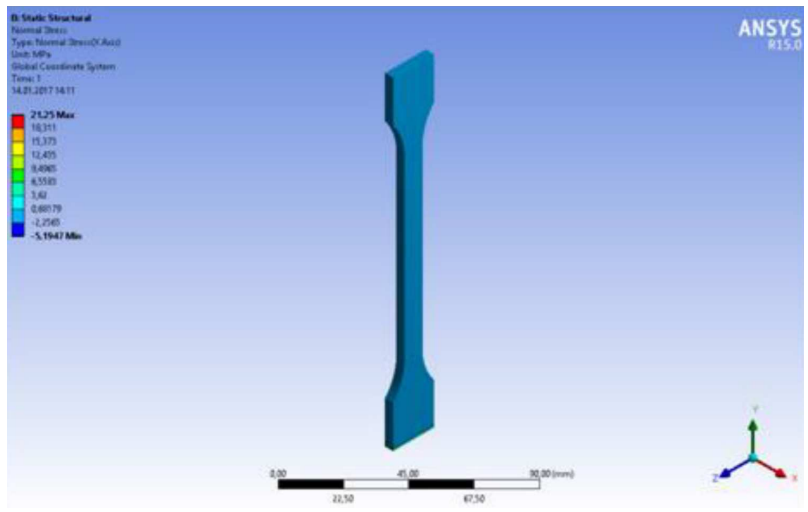

Fig. 7. Distribution of the normal stress (in $\mathrm{MPa}$ ) in the $X$ axis of the sample.

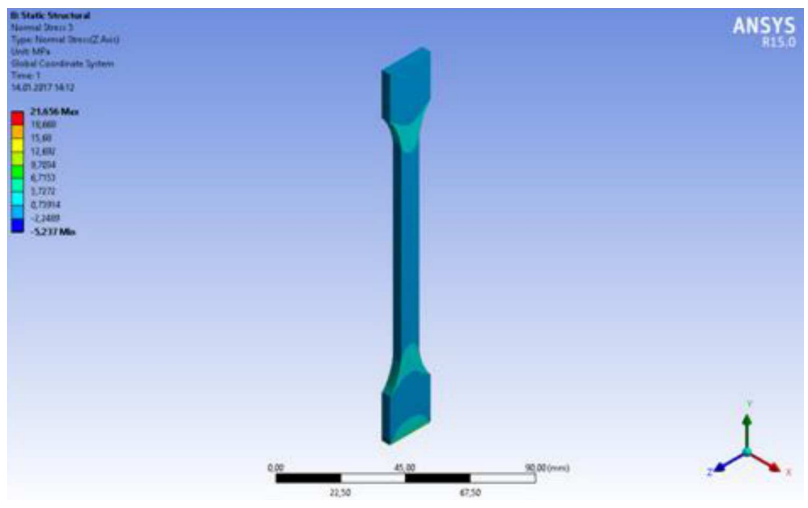

Fig. 8. Distribution of the normal stress (in $\mathrm{MPa}$ ) in the $Z$ axis of the sample.

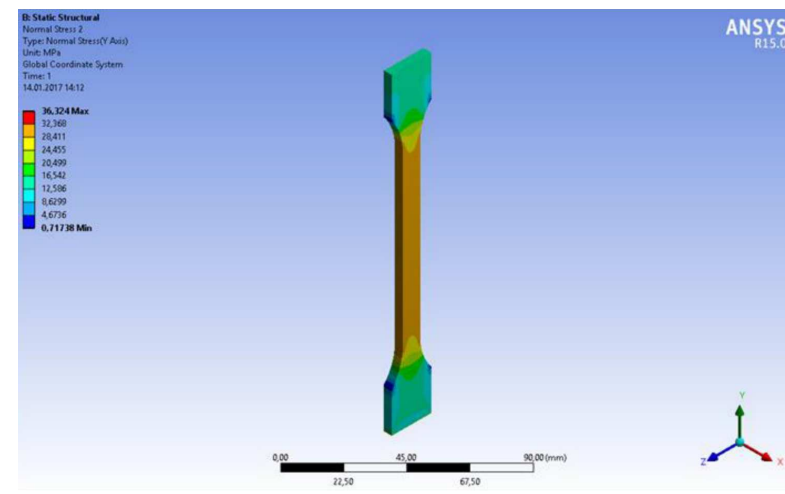

Fig. 9. Distribution of the reduced stress (in $\mathrm{MPa}$ ) in the $Y$ axis of the sample.

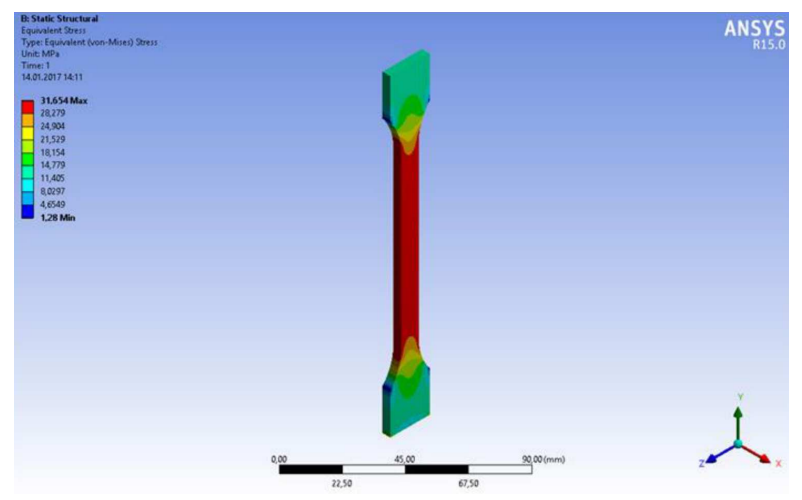

Fig. 10. Distribution of the reduced stress (in MPa) in the $Y$ axis of the sample.

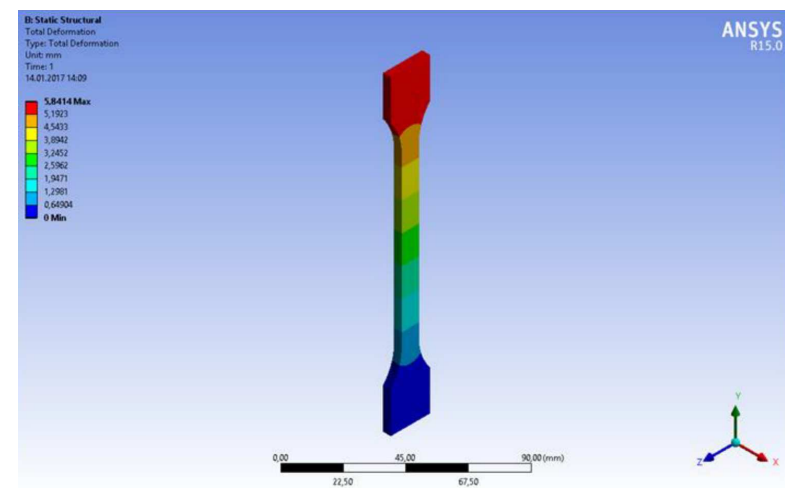

Fig. 11. Total deformation (in $\mathrm{mm}$ ) of the sample.

in the central part of the sample along the so-called test section, where, by default, material continuity is interrupted for the correctly mounted samples and for the appropriately performed test (Fig. 9). Figure 10 shows the distribution of the stresses reduced in the sample subject to simulation, and their value reaches approximately 28-31 MPa; they exceed the value of normal stresses, which results from combining all the constituent stresses existing in the loaded element according to the von Mises hypothesis. 


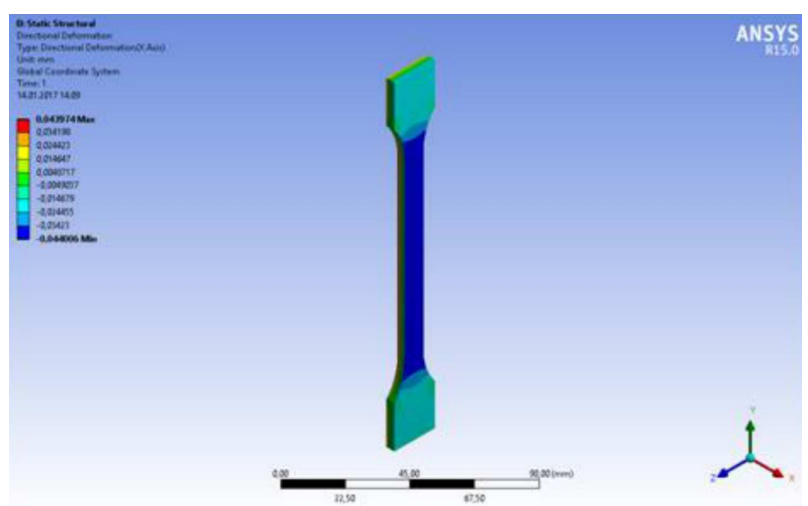

Fig. 12. Deformation of the sample (in $\mathrm{mm}$ ) in the $X$ axis.

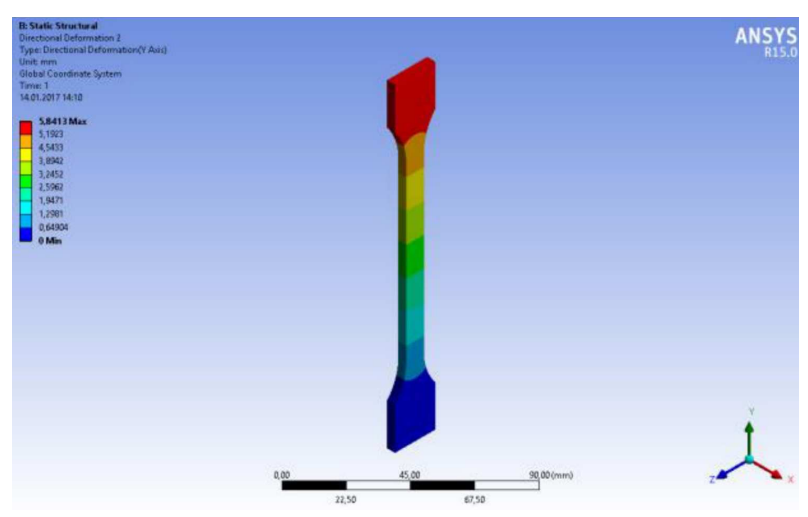

Fig. 13. Deformation of the sample (in $\mathrm{mm}$ ) in the $Y$ axis.

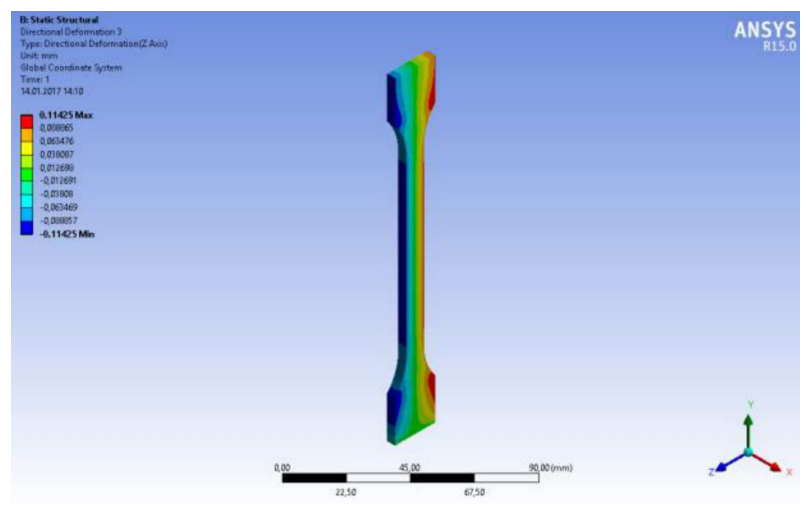

Fig. 14. Deformation of the sample (in $\mathrm{mm}$ ) in the $Z$ axis.

Figure 11 shows sample deformation under the influence of the force applied. It can be concluded by analysing the deformation simulation results that highest deformations will occur in its top part. The highest deformation of approximately $4-5 \mathrm{~mm}$ takes place in the part of the test sample closest to the place of force application, and the force is decreasing in direct proportion to the rising distance from that point, up to the zero value in the holding part situated in the fixed tensile machine jaws, which was immobilised in the simulation. Figures 12-14 show deformations along particular axes of the sample. Again, the highest values are seen for the $Y$ axis, and they range between 4.5 to $5.8 \mathrm{~mm}$ in the upper part of the sample being stretched. However, deformations for the $X$ and $Z$ axes are very small, of 0.04 to $0.1 \mathrm{~mm}$.

\section{Conclusions}

This work presents a simulation of a computer static tensile test carried out using SolidWorks software and then ANSYS software - an engineering tool employing FEM for computations, for samples made of a polyethylene nanocomposite reinforced with particles of a halloysite nanofiller.

It can be concluded in the light of the above results that the stress values and deformation values obtained with computer simulation are similar to the actual results. For maximum stresses $\left(R_{m}\right)$, where a so-called "neck" appears on the test part of the sample, the value of $26 \mathrm{MPa}$ was reached during an actual static tensile test, and the value in simulation was $28 \mathrm{MPa}$. A measurement error for such values was approximately $7 \%$, so the value is relatively small. On the other hand, the values of 8-14 $\mathrm{mm}$ can be observed for sample material deformation for the actual test, however, the deformation value in the simulation was estimated at approximately $5 \mathrm{~mm}$. Such a discrepancy may result from short simulation time in the software $(1 \mathrm{~s})$, while the sections were in fact being stretched for much longer, which allowed for a much greater neck extension along the test part, hence for higher elongation values. This is without influence of the fact, however, that the highest concentration of material stresses and deformations take place in the test part of the sample, which confirms the test assumptions providing that a sample should be broken in the middle part of the so-called dumbbell.

\section{Acknowledgments}

The publication was partially financed by statutory grant from Faculty of Mechanical Engineering, Silesian University of Technology.

\section{References}

[1] G. Herranz, G. Matula, A. Romero, Powder Metall. 60, 120 (2017).

[2] B. Tomiczek, M. Kujawa, G. Matula, M. Kremzer, T. Tański, L.A. Dobrzański, Materialwiss. Werkst. 46, 1 (2015).

[3] K. Gołombek, G. Matula, A.J. Mikuła, M. Sokovic, Mater. Technol. 51, 163 (2017).

[4] A. Katunin, K. Krukiewicz, R. Turczyn, P. Sul, A. Łasica, M. Bilewicz, App. Sur. Sci. 159, 773, (2017). 
[5] P. Jarka, T. Tański, W. Matysiak, E. Krzemiński, B. Hajduk, M. Bilewicz, Appl. Surf. Sci. 424, 206 (2017).

[6] A. Katunin, A. Wronkowicz, M. Bilewicz, D. Wachla, Arch. Civ. Mech. Eng. 17, 806 (2017).

[7] L.A. Dobrzański, M. Macek, B. Tomiczek, P. Nuckowski, A.J. Nowak, Arch. Metall. Mater 61, 1229 (2016).

[8] G. Chladek, K. Basa, J. Żmudzki, P. Malara, A. Nowak, J. Kasperski, Acta Bioeng. Biomech. 18, 43 (2016)

[9] L. A. Dobrzański, A. Pusz, A. J. Nowak, M. Górniak, Arch. Mater. Sci. Eng. 47, 5 (2017)

[10] L. A. Dobrzański, A. Pusz, A. J. Nowak, M. Górniak, J. Achiev. Mater. Manuf. Eng. 46, 18 (2011).

[11] L. A. Dobrzański, A. Pusz, A. J. Nowak, M. Górniak, J. Achiev. Mater. Manuf. Eng. 45, 125. (2011).

[12] K. Matus, M. Pawlyta, G. Matula, K. Gołombek, Arch. Metall. Mater. 61, 747 (2016).

[13] B. Ziębowicz, D. Szewieczek, L.A. Dobrzański, J. Mater. Process. Tech. 175, 457 (2016).

[14] L.W. Żukowska, A. Śliwa, A.J. Mikuła, M. Bonek, W. Kwaśny, M. Sroka, D. Pakuła, Arch. Metall. Mater. 61, 149 (2016).

[15] M. Sroka, A. Zieliński, A.J. Mikuła, Arch. Metall. Mater. 61, 969 (2016).

[16] M. Sroka, M. Nabiałek, M. Szota, A. Zieliński, Rev. Chim. 4, 737 (2017).

[17] A. Śliwa, A. J. Mikuła, K. Gołombek, W. Kwaśny, D. Pakuła, Arch. Metall. Mater. 61, 1371 (2016).

[18] D. Pakuła, M. Staszuk, K. Gołombek, A. Śliwa A.J. Mikuła, Arch. Metall. Mater. 61, 1265 (2016).

[19] A. Śliwa, M. Sroka, K. Bloch, I.G. Sandu, M.M.A. Abdullah, A.V. Sandu, Rev. Chim. 69, 324 (2018).

[20] A. Śliwa, M. Sroka, L. Żukowska, K. Bloch, P. Vizureanu, A.V. Sandu, Rev. Chim. 69, 187 (2018).
[21] M. Staszuk, D. Pakuła, T. Tański, Mater Tehnol 55, 755-759 (2016).

[22] J. Montalvo-Uroquizo, P. Bobrov, A. Schmidt, W. Wosniok, Mech Mater 47, 1 (2012).

[23] N. Benkemoun, M.M.N. Hammood, O. Amiri, Finite Elem. Anal. and Des. 130, 12 (2017).

[24] A. Idesman, A. Bhuiyan, J.R. Foleyle, Finite Elem. Anal. and Des. 126, 26 (2017)

[25] N. Ntallis, K.G. Efthimiadis, Finite Elem. Anal. and Des. 121, 33 (2016).

[26] M. Bonek, A. Śliwa, J. Mikuła, App. Sur. Sci. 388 , 174 (2016).

[27] A. Śliwa, W. Kwaśny, W. Sitek, M. Bonek, Arch Metall. Mater. 61, 481 (2016).

[28] L.A. Dobrzański, A. Śliwa, W. Sitek, in: Proc. 5th International Surface Engineering Congress, ISEC'2006, Seattle (WA) 2006, Ed. M.J. Jackson, ASM International 2006, p. 26.

[29] A. Śliwa, W. Kwaśny, M. Sroka, R. Dziwis, Metalurgija 56, 422 (2017).

[30] M. Sroka, A. Zieliński, A. Hernas, Z. Kania, R. Rozmur, T. Tanski, A. Śliwa,Metalurgija 65, 333 (2017).

[31] A. Śliwa, M. Bonek, Metalurgia 65, 223 (2017).

[32] K. Bouzakis, G. Maliaris, A. Tsouknidas, Comp. Mater. Sci. 59, 133 (2012).

[33] B. Regener, C. Krempaszky, E. Werner, M. Stockinger, Comp. Mater. Sci. 52, 77 (2012).

[34] Y. Kim, S. Yaan, D. Shan, S. Choi, S. Lee, B. You, J. Mater. Eng. Perfor., 257 (2006).

[35] S. Thipprakmas, M. Jin, K. Tomokazu, Y. Katsuhiro, M. Murakawa, J. Mater. Process. Tech. 198, 391 (2008).

[36] Z. Tong, Y. Zhang, H. Hua, J. Sound Vib. 299, 645 (2007). 